\title{
RESISTIVITAS BATUAN BERDASARKAN METODE GEOLISTRIK KONFIGURASI SCHLUMBERGER UNTUK MENENTUKAN POTENSI AIR TANAH SEBAGAI ACUAN SUMUR BOR
}

\author{
Fadilah
}

Institut Agama Islam Negeri Bengkulu

\begin{abstract}
The purpose of this study is to analyze rock resistivity based on the geoelectric method of the Schlumberger configuration to determine the potential for groundwater as a reference for boreholes. The method used in this research is the geoelectric resistivity method with a Schlumberger configuration. Data acquisition modeling was analyzed using Progress Version 3.0 to describe the subsurface based on measurement sounding points in the field. The main targets for these measurements are confined aquifer traps and sandstone stratigraphy. Field measurement points are at coordinates S 03043 '52.2 "and E 1020 19' 27.1". The results of this study indicate that the layer that is thought to be the groundwater carrier layer is found at a depth of about 64.99 meters to 150.86 meters with a layer thickness of 85.87 meters, which is in the form of sandstone density with a resistivity value of $5.39 \mathrm{ohm}$ meters. The iteration error scale value in this study is, $5.05 \%$ RMS. In conclusion, the results obtained can provide specific information for groundwater drilling actors in the research location.
\end{abstract}

Keywords: Groundwater, Geoelectricity, Resistivity, Schlumberger

\begin{abstract}
Abstrak: Tujuan penelitian ini adalah untuk menganalisis resistivitas batuan berdasarkan metode geolistrik konfigurasi Schlumberger untuk menentukan potensi air tanah sebagai acuan sumur bor. Metode yang digunakan pada penelitian ini adalah metode geolistrik resistivitas dengan konfigurasi Schlumberger. Pemodelan data akuisisi dianalisis menggunakan Progress Version 3.0 untuk menggambarkan bawah permukaan berdasarkan titik sounding pengukuran di lapangan. Target utama pengukuran ini adalah jebakan confined aquifer dan stratigrafi batu pasir. Titik pengukuran lapangan berada pada koordinat S 030 43' 52,2"' dan E 1020 19'27,1'. Hasil penelitian ini menunjukkan bahwa lapisan yang diduga sebagai lapisan pembawa air tanah terdapat pada kedalaman sekitar 64,99 meter sampai dengan 150,86 meter dengan ketebalan lapisan 85,87 meter, yaitu berupa keterdapatan batuan pasir dengan nilai resistivitas 5,39 ohm meter. Nilai skala kesalahan iterasi pada penelitian ini adalah, 5,05\% RMS. Simpulan, hasil yang diperoleh dapat memberikan informasi khusus bagi pelaku pengeboran air tanah di wilayah lokasi penelitian.
\end{abstract}

Kata Kunci: Air Tanah, Geolistrik, Resistivitas, Schlumberger

\section{PENDAHULUAN}

Air merupakan salah satu sumberdaya alam yang sangat penting bagi kelangsungan kehidupan makhluk di muka bumi. Air memiliki banyak manfaat di berbagai sektor, selain untuk dikonsumsi. Ketersediaan air di bumi tidak tersebar secara merata melainkan bervariasi jumlah dan lokasinya. Oleh karena itu, keberadaan sumberdaya air harus dilindungi dan dimanfaatkan dengan bijaksana oleh manusia agar tercapai keberlanjutan kehidupan yang seimbang. Hal ini dapat tercapai apabila penggunaan air dilakukan dengan cara hemat dan tepat guna demi kelestarian lingkungan pada generasi yang akan datang.

Berdasarkan kondisi geografis, sumber daya air Indonesia termasuk dalam kawasan tropika basah dengan curah hujan rata-rata tinggi, yaitu sebesar $2.600 \mathrm{~mm}$ dengan variasi antara 1.500 sampai 3.000 mm (Suripin, 2001). Dari besarnya curah hujan rata-rata tahunan di seluruh kawasan Indonesia sebagian hilang dan sebagian lainnya mengalir. Berdasarkan letaknya, air dapat dibagi menjadi 2 (dua) yaitu air permukaan dan air tanah. Air permukaan dapat lebih mudah dilihat dan diketahui jumlah dan keberadaannya karena terletak di permukaan sedangkan air tanah 
memerlukan pengamatan yang lebih teliti untuk mengetahui jumlah dan potensinya .

Salah satu cara untuk mengetahui keberadaan dan potensi air tanah adalah dengan aplikasi metode geofisika yaitu geolistrik resistivitas (tahanan jenis). Metode ini mendeteksi variasi nilai resistivitas pada perlapisan batuan yang mencakup daerah pengukuran sebanding dengan kedalamannya (Telford et al., 1990). Nilai resistivitas dapat merepresentasikan keberadaan air tanah di suatu wilayah. Confined aquifer adalah keterdapatan air tanah yang diapit oleh dua lapisan yang bersifat akuiklud dan memiliki tekanan air lebih besar dari tekanan atmosfer. Lapisan confined aquifer bersifat permeable yaitu berpori dan mampu mengalirkan fluida.

Desa Tanjung Terdana terletak di Kecamatan Pondok Kubang, Kabupaten Bengkulu Tengah, Provinsi Bengkulu. Pada wilayah ini akan dibangun sebuah Pondok Pesantren, khususnya berada pada lokasi perkebunan kelapa sawit yang jauh dari pemukiman penduduk. Pada titik ini belum pernah dilakukan pemboran air tanah dalam rangka sumber air untuk kelangsungan aktifitas manusia.

Penelitian ini bertujuan untuk menemukan kedalaman dan potensi air tanah pada lokasi pengukuran sebagai acuan sumur bor berdasarkan analisis resistivitas menggunakan Progress Version 3.0. Pemilihan Progress Version 3.0 ini disebabkan biaya analisis cukup murah dan efisien untuk menemukan gambaran bawah permukaan dan kedalaman perlapisan batuan pembawa air tanah, hanya dengan melakukan satu titik akuisisi data. Cakupan penelitian ini dibatasi pada kedalaman dan ketebalan perlapisan batuan sebagai confined aquifer.

Penelitian sebelumnya dilakukan oleh Halik \& Widodo (2008) yang mengkaji pendugaan potensi air tanah dengan metode geolistrik konfigurasi Schlumberger di kampus Tegal Boto Universitas Jember. Hasil penelitian tersebut menunjukkan bahwa metode geolistrik konfigurasi Schlumberger dapat digunakan untuk memperkirakan Keterusan dan kedalaman muka air tanah.

Selain itu, Azwar (2009) juga menerapkan metode geolistrik konfigurasi Schlumberger untuk pemodelan lapisan air tanah dalam (akuifer). Hasilnya, metode geolistrik konfigurasi Schlumberger juga dapat menggambarkan jenis dan arah aliran akuifer. Hal tersebut lah yang mendasari ketertarikan peneliti untuk menerapkan metode geolistrik konfigurasi Schlumberger pada penelitian ini untuk menemukan kedalaman dan potensi air tanah pada lokasi pengukuran sebagai acuan sumur bor.

\section{LANDASAN TEORI}

Ketersediaan air di suatu daerah merupakan hal yang sangat penting bagi makhluk hidup sebagai upaya untuk memenuhi kebutuhan hidupnya. Salah satu sumber air yang digunakan adalah air tanah (Abidin, 2004). Air tanah ini dapat tersebar di berbagai macam lapisan, diantaranya yaitu endapan aluvial, batuangamping dan batu pasir. Air tanah merupakan salah satu sumber daya alam yang dapat diperbaharui, namun diperlukan waktu yang relatif lama untuk mengalami pengisian kembali. Hal itu bergantung pada kondisi permukaan, litologi, topografi, dan kedalaman muka air tanah (Zeffitni, 2011).

Metode geolistrik merupakan salah satu metode geofisika yang mempelajari sifat aliran listrik di bawah permukaan dan untuk pendugaan keadaan di bawah permukaan, seperti pendugaan jenis bahan penyusun batuan. Pada dasarnya sistem panas bumi terbentuk sebagai hasil perpindahan panas dari suatu sumber panas ke sekelilingnya yang terjadi secara konduksi dan secara konveksi. Perpindahan panas secara konduksi terjadi melalui batuan, sedangkan perpindahan panas secara konveksi terjadi karena adanya kontak antara air dengan suatu sumber panas. Perpindahan panas secara 
konveksi pada dasarnya terjadi karena gaya apung (bouyancy). Air karena gaya gravitasi selalu mempunyai kecenderungan untuk bergerak ke bawah, akan tetapi apabila air tersebut kontak dengan suatu sumber panas maka akan terjadi perpindahan panas sehingga temperatur air menjadi lebih (Harefa \& Simamora, 2013).

Nilai resistivitas pada batuan ini sangat variatif. Untuk mineral logam nilai nya berkisar pada 105 Ohm meter. Begitu juga untuk batuan-batuan lain, komposisi batuan akan mempengaruhi rentang nilai resistivitas terhadap batuan itu. Suatu bahan dengan resistivitas kurang dari 10-5 Ohm meter biasanya didefinisikan sebagai konduktor, sedangkan isolator jika resistivitasnya lebih dari 107 Ohm meter (Dwiharto \& Purwanto, 2017).

\section{METODE PENELITIAN}

Metode yang digunakan pada penelitian ini adalah metode geolistrik resistivitas dengan konfigurasi Schlumberger. Pemodelan data akuisisi dianalisis menggunakan Progress Version 3.0 untuk menggambarkan bawah permukaan berdasarkan titik sounding pengukuran di lapangan. Target utama pengukuran ini adalah jebakan confined aquifer dan stratigrafi batu pasir. Titik pengukuran lapangan berada pada koordinat S 030 43' 52,2" dan E 1020 19' 27,1 "

Data yang digunakan untuk penelitian ini diperoleh dari pengukuran di lapangan menggunakan satu unit alat ukur Geolistrik Resistivitas Naniura. Akusisi data menggunakan metode geolistrik dengan konfigurasi schlumberger. Hasil pengukuran lapangan diperoleh data berupa nilai resistivitas. Data resistivitas tersebut dikalibrasi dengan nilai konstanta tertentu untuk mendapatkan nilai resistivitas semu pada setiap perlapisan batuannya.

Konfigurasi metode geolistrik yang digunakan pada penelitian ini konfigurasi Schlumberger, yakni menggunakan 4 buah elektroda yang terletak dalam satu garis lurus serta simetris terhadap titik tengah. Elektroda arus (AB) diletakkan di bagian luar sebanyak 2 (dua) batang, sedangkan elektroda potensial (MN) diletakkan pada bagian dalam sebanyak 2 (dua) batang. Kombinasi dari jarak $\mathrm{AB} / 2$, jarak $\mathrm{MN} / 2$, besarnya arus listrik yang dialirkan serta tegangan listrik yang terjadi akan didapat suatu harga tahanan jenis semu (Apparent Resistivity) (Gambar 1). Disebut tahanan jenis semu karena tahanan jenis yang terhitung tersebut merupakan gabungan dari banyak lapisan batuan di bawah permukaan yang dilalui arus listrik.

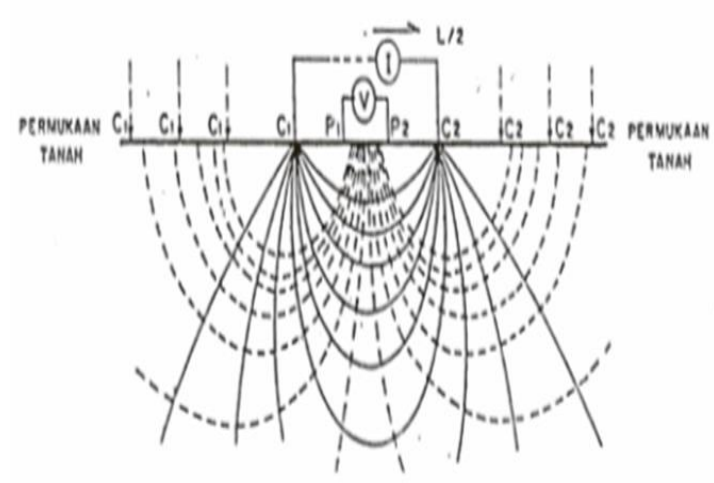

Gambar 1. Skema Konfigurasi Schlumberger

Pengukuran beda potensial antara dua elektroda tersebut dapat dihitung tahanan jenis semua batuan dengan menggunakan rumus sebagai berikut (Todd, 1980):

$$
\rho_{a}=k \frac{\Delta V}{I}
$$

Keterangan: $\rho_{a}=$ Tahanan Jenis (ohmm); $k=$ Konstanta; $V=$ beda potensial (Volt); $I=$ arus (ampere).

Bila satu set hasil pengukuran tahanan jenis semu dari jarak $A B$ terpendek sampai yang terpanjang tersebut digambarkan pada grafik logaritma ganda dengan jarak $A B / 2$ sebagai sumbu-X dan tahanan jenis semu sebagai sumbu $\mathrm{Y}$, maka akan didapat suatu bentuk kurva data geolistrik. Nilai resistivitas sebenarnya hasil akuisisi dapat dilakukan dengan pencocokan (matching) atau dengan metode inversi. 
Setelah dilakukan pencatatan data dari akuisisi di lapangan, selanjutnya data tersebut diolah menggunakan software Progress Version 3.0. Data yang dimasukkan ke dalam software ini ada $\mathrm{AB} / 2$ dan resistivitas semu yag telah diukur. Hasil pengolahannya berupa data sounding yaitu ketebalan lapisan, kedalaman dan nilai resistivitas sesungguhnya pada arah vertikal.

Interpretasi nilai resistivitas dengan mengasumsikan bahwa bumi bersifat homogen isotrop dan mempunyai ketebalan tertentu dalam setiap lapisan tanahnya, sedangkan batas antar lapisan dianggap horizontal dan berasosiasi dengan kondisi geologi tertentu.

Tabel 1. Konversi Nilai Tahanan Jenis

\begin{tabular}{lll}
\hline No & \multicolumn{1}{c}{ Material } & Resistivty meter (Ohm-meter) \\
\hline 1 & Udara & - \\
2 & Pyrite (pirit) & $0.001-100$ \\
3 & Quartz (kwarsa) & $500-800.000$ \\
4 & Calcite (Kalsit) & $1 \times 10^{12}-1 \times 10^{13}$ \\
5 & Rock Slat (Batu garam) & $30-1 \times 10^{13}$ \\
6 & Granite (Granit) & $200-100.000$ \\
7 & Andesite (Andesit) & $1.7 \times 10^{2}-45 \times 10^{4}$ \\
8 & Basalt & $200-100.000$ \\
9 & Limestone (Gamping) & $500-10.000$ \\
10 & Sandstone (Batu pasir) & $200-8.000$ \\
11 & Shales & $20-2.000$ \\
12 & Sand (Pasir) & $1-1.000$ \\
13 & Clay (Lempung) & $1-1.00$ \\
14 & Ground Water (Air tanah) & $0.5-300$ \\
15 & Sea Water (Air laut) & 0.2 \\
16 & Magnetite (Magnetit) & $0.01-1.000$ \\
17 & Dry Gravel (Kerikil kering) & $600-10.000$ \\
18 & Alluvium & $10-800$ \\
19 & Gravel (Kerikil) & $100-600$ \\
\hline
\end{tabular}

(Sumber: Telford, et,al., 1990)

\section{HASIL PENELITIAN}

Pengukuran geolistrik dilakukan di Desa Tanjung Terdana, Kecamatan Pondok Kubang, Kabupaten Bengkulu Tengah, Provinsi Bengkulu. Panjang lintasan pengukuran sejauh \pm 400 meter. Spasi pengukuran menggunakan konfigurasi Schlumberger. Keadaan cuaca saat pengukuran cerah-panas. Koordinat titik pengukuran S 030 43' 52,2" dan E $102^{0} 19$ ' 27,1 " dengan arah bentangan tenggara $\mathrm{S} 110^{\circ} \mathrm{E}$.

Data lapangan terpilih kemudian diimpor ke dalam Progress Version 3.0. Proses picking dilakukan untuk memperoleh grafik hubungan resistivitas dan arus terhadap kedalaman. Hasil yang diperoleh ditunjukkan dalam kurva dan log resistivitas batuan terhadap kedalaman (Gambar 2).

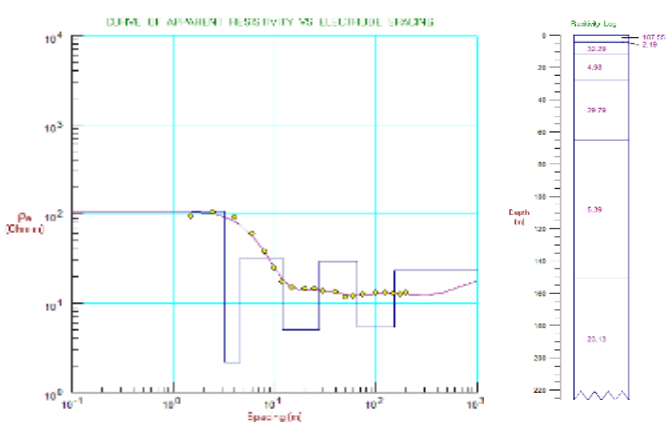

Gambar 2. Kurva dan Log Resistivitas Batuan terhadap Kedalaman

Parameter resistivitas pada kedalaman perlapisan diperoleh 7 perlapisan dengan nilai Root Mean Square (RMS) 5,05\%. Hal ini lebih jelas tersaji 
dalam tabel parameter model perlapisan batuan (tabel 2).

Tabel 2. Parameter Model Perlapisan Batuan

\begin{tabular}{ccc}
\hline \multicolumn{3}{c}{ Model Parameter } \\
\hline Layer & Depth & Resistivity \\
\hline 1 & 0,00 & 107.55 \\
2 & 3.24 & 2.19 \\
3 & 4.62 & 32.29 \\
4 & 11.92 & 4.98
\end{tabular}

Tabel 3. Deskripsi Perlapisan Batuan pada Lokasi Penelitian

\begin{tabular}{|c|c|c|c|c|}
\hline $\begin{array}{l}\text { Lapisan } \\
\text { Ke- }\end{array}$ & Kedalaman (m) & $\begin{array}{l}\text { Ketebalan } \\
(\mathrm{m})\end{array}$ & $\begin{array}{l}\text { Resistivitas } \\
\text { (ohmm) }\end{array}$ & Deskripsi Lap. Batuan \\
\hline 1 & $0-3,24$ & 3,24 & 107,55 & $\begin{array}{c}\text { Lapisan penutup, alluvial, pasir, } \\
\text { kerakal }\end{array}$ \\
\hline 2 & $3,24-4,62$ & 1,38 & 2,19 & $\begin{array}{c}\text { Pasir lempungan, kondisi basah } \\
\text { lembek }\end{array}$ \\
\hline 3 & $4,62-11,92$ & 7,3 & 32,29 & $\begin{array}{l}\text { Lapukan soil, lempung, pasir, } \\
\text { batuan masif keras }\end{array}$ \\
\hline 4 & $11,92-27,55$ & 15,62 & 4,98 & $\begin{array}{c}\text { Pasir, lempung, mengandung air, } \\
\text { diduga sebagai lapisan pembawa } \\
\text { air tanah dangkal }\end{array}$ \\
\hline 5 & $27,55-64,99$ & 37,44 & 29,79 & $\begin{array}{c}\text { Lapukan soil, lempung, pasir, } \\
\text { batuan keras }\end{array}$ \\
\hline 6 & $64,99-150,86$ & 85,87 & 5,39 & $\begin{array}{c}\text { Pasir, lempung, mengandung air, } \\
\text { diduga sebagai lapisan pembawa } \\
\text { air tanah dalam }\end{array}$ \\
\hline 7 & $>150,86$ & $\sim$ & 23,13 & $\begin{array}{l}\text { Lapukan soil, lempung, pasir, } \\
\text { batuan keras }\end{array}$ \\
\hline
\end{tabular}

Berdasarkan hasil pengolahan data lapangan dan deskripsi perlapisan batuan pada titik ini, lapisan yang diduga sebagai lapisan pembawa air tanah terdapat pada kedalaman sekitar 65-150 meter, yaitu terdapat batuan pasir berlempung. Selanjutnya untuk penentuan titik bor dilakukan pada lokasi dugaan air dengan memperhatikan perubahan jenis batuan pada setiap perlapisan sehingga pengeboran perlu dilakukan hingga kedalaman sekitar 70-120 meter dan pemasangan saringan sebaiknya dilakukan pada kedalaman sekitar 60-90 meter.

\section{PEMBAHASAN}

Berdasarkan hasil pendugaan tahanan jenis lapisan batuan, yang ditunjang oleh data geologi permukaan dan

\begin{tabular}{ccc}
5 & 27.55 & 29.79 \\
6 & 64.99 & 5.39 \\
7 & 150.86 & 23.13 \\
\hline \multicolumn{4}{c}{ Berdasarkan data } & pada & tabel 2,
\end{tabular}
analisis progress version 3.0 dapat menjabarkan deskripsi perlapisan batuan sebagai gambar bawah permukaan untuk menemukan kedalaman dan potensi air tanah pada lokasi penelitian (tabel 3). data hidrogeologi daerah setempat, maka pendugaan geolistrik dapat memberikan gambaran bawah permukaan tentang susunan, penyebaran dan ketebalan lapisan batuan yang diduga dapat bertindak sebagai lapisan pembawa air berdasarkan sifat tahanan jenisnya. Gambaran potensi sumber air yang diperoleh pada penelitian ini sejalan dengan hasil temuan Budiman et al., (2013) bahwa dengan menerapkan metode Schlumberger ia juga memperoleh gambaran mengenai lapisan tanah penutup, lapisan batu pasir, lapisan lempung pasiran dan lapisan batu pasir vulkanik serta jenis akuifer pada daerah penelitiannya yaitu di Jorong Tampus Kanagarian Ujung Gading Kecamatan Lembah Malintang Kabupaten Pasaman Barat Sumatera Barat. 
Prinsip konfigurasi Schlumberger yang digunakan pada penelitian ini yaitu dengan cara mengkondisikan spasi antar elektroda potesial adalah tetap sedangkan spasi antar elektroda arus berubah secara bertahap (Sheriff, 2002). Prinsip ini dilakukan dengan cara memindahkan elektroda dengan jarak tertentu sehingga diperoleh nilai resistivitas batuan pada kedalaman tertentu yang sesuai dengan jarak elektroda.

Resistivitas sendiri merupakan suatu besaran yang menunjukkan tingkat hambatan terhadap arus listrik terhadap suatu bahan. Sifat khas dari suatu material adalah memiliki resistivitas yaitu besaran yang menunjukkan tingkat hambatan material terhadap arus listrik. Pendekatan yang digunakan untuk mendapatkan resistivitas setiap medium di bawah permukaan bumi yaitu dengan mengasumsikan bahwa bumi merupakan suatu medium yang homogen isotropis (Bahri, 2005).

\section{SIMPULAN}

Berdasarkan hasil pendugaan tahanan jenis lapisan batuan, yang ditunjang oleh data geologi permukaan dan data hidrogeologi daerah setempat, maka pendugaan geolistrik dapat memberikan gambaran bawah permukaan tentang susunan, penyebaran dan ketebalan lapisan batuan yang diduga dapat bertindak sebagai lapisan pembawa air berdasarkan sifat tahanan jenisnya. Namun untuk mengetahui besar kecilnya potensi air bawah tanah setempat, maka perlu dilakukan pemboran eksplorasi dan uji pemompaan dengan tujuan memastikan kedudukan lapisan pembawa air tanah yang berperan penting dalam menentukan penempatan saringan (screen) dan mengetahui kapasitas potensi jenis lapisan pembawa air.

\section{DAFTAR PUSTAKA}

Abidin, R. (2004). Identifikasi Sebaran Air Tanah Berdasarkan Karakteristik Geomorfologi Menggunakan Citra
Landsat 7 ETM di Kabupaten

Sidoarjo. Undergaduate Theses.

Institut Teknologi Sepuluh

November

Azwar, H. (2009). Pemodelan Lapisan Air

Tanah Dalam (Akuifer) di Desa

Telogorejo Kabupaten Demak

Berdasarkan Data Tahanan Jenis.

Skripsi. Universitas Islam Negeri

Syarif Hidayatullah

Bahri, B. (2005). Hand Out Mata Kuliah Geofisika Lingkungan dengan topik Metoda Geolistrik Resistivitas. Institut Teknologi Sepuluh November: Fakultas Matematika dan Ilmu Pengetahuan Alam

Budiman, A., Delhasni, D., \& Widjojo, S.A.H. S. (2013). Pendugaan Potensi Air Tanah dengan Metode Geolistrik Tahanan Jenis Konfigurasi Schlumberger (Jorong Tampus Kanagarian Ujung Gading Kecamatan Lembah Malintang Kabupaten Pasaman Barat, Sumatera Barat). Jurnal Ilmu Fisika (JIF), 5(2), 72-78

Dwiharto, M. F., \& Purwanto, M. S. (2017). Penerapan Metode Resistivitas 2D untuk Identifikasi Bawah Permukaan Situs Maelang Bayuwangi Jawa Timur. Jurnal Sains dan Seni ITS, 6(2), 23373520

Halik, G., \& Widodo J. S. (2008). Pendugaan Potensi Air Tanah dengan Metode Geolistrik Konfigurasi Schlumberger di Kampus Tegal Boto Universitas Jember. Media Teknik Sipil, 8(2), 109-114

Harefa, E. B., \& Simamora, P. (2013). Analisis Resistivitas Batuan dan Fluida di Bawah Permukaan dengan Metode Geolistrik Schlumberger di Daerah Panas Bumi Desa Huta Baru Sipirok Tapanuli Selatan. Jurnal Einstein, 1(2), 57-63

Sheriff, R. E. (2002). Encyclopedic Dictionary of Applied Geophysics 
Fourth Edition. Tulsa: The Society of Exploration Geophysicists (SEG)

Suripin, S. (2001). Pelestarian Sumber Daya Tanah dan Air. Yogyakarta: Andi

Telford, W. M., Geldart, L. P., Sheriff, R. E., \& Keys, D. A. (1990). Applied Geophysics Second Edition. Cambridge: Cambridge University Press
Todd, D. K. (1980). Grounwater Hydrology Second Edition, Associate Professor of Civil Engineering California University. New York: John Wiley \& Sons

Zeffitni, Z. (2011). Identifikasi Batas Lateral Cekungan Air Tanah (CAT) Palu. Jurnal SMARTek, 9(4), 337-349 